\title{
Mechanism of Heterogeneous Reaction of Carbonyl Sulfide on Magnesium Oxide
}

\author{
Yongchun Liu, Hong He,* Wenqing $\mathrm{Xu}$, and Yunbo Yu \\ State Key Laboratory of Environmental Chemistry and Ecotoxicology, Research Center for Eco-Environmental \\ Science, Chinese Academy of Sciences, Beijing 100085, China
}

Received: December 29, 2006; In Final Form: March 13, 2007

\begin{abstract}
Heterogeneous reaction of carbonyl sulfide (OCS) on magnesium oxide $(\mathrm{MgO})$ under ambient conditions was investigated by in situ diffuse reflectance infrared Fourier transform spectroscopy (DRIFTS), quadrupole mass spectrometer (QMS), and density functional theory (DFT) calculations. It reveals that OCS can be catalytically hydrolyzed by surface hydroxyl on $\mathrm{MgO}$ to produce carbon dioxide $\left(\mathrm{CO}_{2}\right)$ and hydrogen sulfide $\left(\mathrm{H}_{2} \mathrm{~S}\right)$, and then $\mathrm{H}_{2} \mathrm{~S}$ can be further catalytically oxidized by surface oxygen or gaseous oxygen on $\mathrm{MgO}$ to form sulfite $\left(\mathrm{SO}_{3}{ }^{2-}\right)$ and sulfate $\left(\mathrm{SO}_{4}{ }^{2-}\right)$. Hydrogen thiocarbonate $\left(\mathrm{HSCO}_{2}{ }^{-}\right)$was found to be the crucial intermediate. Surface hydrogen sulfide (HS), sulfur dioxide $\left(\mathrm{SO}_{2}\right)$, and surface sulfite $\left(\mathrm{SO}_{3}{ }^{2-}\right)$ were also found to be intermediates for the formation of sulfate. Furthermore, the surface hydroxyl contributes not only to the formation of $\mathrm{HSCO}_{2}{ }^{-}$but also to $\mathrm{HSCO}_{2}{ }^{-}$decomposition. On the basis of experimental results, the heterogeneous reaction mechanism of OCS on $\mathrm{MgO}$ was discussed.
\end{abstract}

\section{Introduction}

Carbonyl sulfide (OCS) is the most abundant sulfur compound in the atmosphere, with a rather uniform mixing ratio of about 500 pptv (parts per trillion by volume) in the troposphere. ${ }^{1-3}$ Its tropospheric lifetime is greater than 1 year ${ }^{1,2}$ and the global atmospheric lifetime is from 2 to 8.9 years calculated by different researchers. ${ }^{2,4}$ Chin and Davis ${ }^{2}$ have reported that about $0.64 \mathrm{Tg} \cdot \mathrm{yr}^{-1}$ of OCS is transported to stratosphere from troposphere, where its photolysis is the important source of stratospheric sulfate layer ${ }^{5}$ and sustains the Junge layer. Therefore, it is of interest to investigate the sources and sinks of OCS.

By now, numerous sinks have been identified, such as oxic soils, vegetation, homogeneous reaction with $\mathrm{OH}$ and $\mathrm{O}$, and photolysis. ${ }^{1-6}$ In recent years, there has been a great deal of interest in the heterogeneous chemistry of trace atmospheric gases on atmospheric particulates in the troposphere. ${ }^{7-9}$ It is estimated that 3000-5000 $\mathrm{Tg}$ of particulate matter, in the form of soil dust, sea salt, organics, sulfate aerosol, and soot, and $1000-3000 \mathrm{Tg}$ of mineral aerosols are emitted annually into the atmosphere. ${ }^{10}$ On the other hand, atmospheric particulates have a large specific surface area, usually greater than 1 $\mathrm{m}^{2} \cdot \mathrm{g}^{-1} \cdot{ }^{11,12}$ Therefore, abundant and diverse atmospheric particulates can facilitate heterogeneous chemistry in the troposphere. More recently, a few studies have reported the heterogeneous reaction of OCS on atmospheric particles, $\mathrm{Al}_{2} \mathrm{O}_{3}, \mathrm{SiO}_{2}$, $\mathrm{Fe}_{2} \mathrm{O}_{3}, \mathrm{CaO}$, and $\mathrm{MnO}_{2}$ at room temperature. ${ }^{13-16} \mathrm{MgO}$ is also a typical component of atmospheric particulates, whose content is about $6.1 \mathrm{wt} \%$ of the inorganic components in the Beijing area. ${ }^{13,17}$ However, the reaction of OCS on $\mathrm{MgO}$ has not been reported yet. Therefore, it is significant to investigate the heterogeneous reaction of OCS on $\mathrm{MgO}$ to further understand the heterogeneous reaction of OCS on atmospheric particles.

In this paper, diffuse reflectance infrared Fourier transform spectroscopy (DRIFTS), quadrupole mass spectroscopy (QMS),

* Corresponding author: phone +86-10-62849123; fax +86-1062923563; e-mail honghe@rcees.ac.cn. and density functional theory (DFT) calculations were used to study the reaction mechanism of OCS on $\mathrm{MgO}$. We found that $\mathrm{MgO}$ can catalyze the heterogeneous reaction of OCS under ambient conditions. Based on the information of intermediates and final products, a reaction mechanism was proposed.

\section{Experimental Section}

2.1. Materials. The $\mathrm{MgO}$ sample (A.R.) used in this experiment was supplied by Haizhong Chemical Plant in Tianjin. The impurities in $\mathrm{MgO}$ sample include $\mathrm{Cl}(0.01 \%), \mathrm{SO}_{4}{ }^{2-}$ $(0.02 \%), \mathrm{PO}_{4}{ }^{3-}(0.003 \%), \mathrm{CO}_{3}{ }^{2-}(1.5 \%), \mathrm{Na}(0.05 \%), \mathrm{K}$ $(0.005 \%), \mathrm{Ca}(0.02 \%), \mathrm{Fe}(0.005 \%), \mathrm{Cu}(0.001 \%), \mathrm{Zn}(0.005 \%)$, As $(0.0001 \%)$, and $\mathrm{Ba}$ and $\mathrm{Sr}(0.005 \%)$. Before the DRIFTS measurement, the sample was pretreated in an in situ infrared chamber at $573 \mathrm{~K}$ in $100 \mathrm{~mL} \cdot \mathrm{min}^{-1} \mathrm{~N}_{2}$ stream for $2 \mathrm{~h}$.

All chemicals were used without further purification as follows: carbonyl sulfide (OCS, $2 \%, \mathrm{OCS} / \mathrm{N}_{2}$, Scott Specialty Gases Inc.), $\mathrm{N}_{2}$ and $\mathrm{O}_{2}$ (99.99\% purity, Beijing AP BEIFEN Gases Inc.), and $\mathrm{P}_{2} \mathrm{O}_{5}$ (A. R., The Sixth Chemical Plant in Tianjin).

2.2. Characterization of Sample. Nitrogen BrunauerEmmett-Teller (BET) physisorption measurement was performed by use of Micromeritics ASAP 2000 automatic equipment. It was shown that the $\mathrm{MgO}$ sample has a total surface area of $14.6 \mathrm{~m}^{2} \cdot \mathrm{g}^{-1}$. The X-ray powder diffraction pattern was collected from $10^{\circ}$ to $90^{\circ} 2 \theta$ on a D/max-RB automatic powder $\mathrm{X}$-ray diffractometer using $\mathrm{Cu} \mathrm{K} \alpha$ irradiation. The sample was identified to be periclase with the three main $2 \theta$ peaks at $42.918^{\circ}, 62.300^{\circ}$, and $78.622^{\circ}$. The diameter distribution was measured with a laser particle size analyzer, Masterizer 2000. The diameter was from 400 to $2500 \mu \mathrm{m}$ with an average diameter of $759 \mu \mathrm{m}$.

2.3 Experimental Methods. In situ DRIFTS spectra were recorded on a NEXUS 670 (Thermo Nicolet Instrument Corp.) Fourier transform infrared (FT-IR) spectrometer, equipped with an in situ diffuse reflection chamber and a high-sensitivity mercury-cadmium-telluride (MCT) detector cooled by liquid $\mathrm{N}_{2}$. The reference spectrum was measured after the pretreated 
sample was cooled to $303 \mathrm{~K}$ in nitrogen stream or simulated air. The infrared spectra were collected and analyzed by a computer with OMNIC 6.0 software. All spectra reported here were recorded at a resolution of $4 \mathrm{~cm}^{-1}$ for 100 scans.

The $\mathrm{MgO}$ sample (about $10 \mathrm{mg}$ ) for the in situ DRIFTS studies was finely ground and placed into a ceramic crucible in the in situ chamber. The total flow rate was $100 \mathrm{~mL} \cdot \mathrm{min}^{-1}$ in all of the flow systems, and the volume of reactor chamber in the closed system was $30 \mathrm{~mL} . \mathrm{N}_{2}(79 \%)$ and $\mathrm{O}_{2}(21 \%)$ were mixed to simulate the composition of air. In all experiments, $2.0 \% \mathrm{OCS} / \mathrm{N}_{2}$ was diluted to $1000 \mathrm{ppmv}$ with high-purity $\mathrm{N}_{2}$ or simulated air. Unless declared specially, the feed gas was not dried and is marked as moist OCS/air or moist OCS/ $\mathrm{N}_{2}$. The content of water in the feed gas was measured with a hygrometer, but it is lower than the lower limit of the hygrometer. In order to investigate the influence of water and surface hydroxyl on the reaction, reactant gases were dried with $\mathrm{P}_{2} \mathrm{O}_{5}$ and are marked as dry OCS/air or dry OCS/ $\mathrm{N}_{2}$. Gaseous products were determined on-line with a Hiden HPR20 QMS in flow system.

DFT calculations were performed to identify the intermediates. The Gaussian 98 program $^{18}$ was performed to optimize the structures and calculate the vibrational frequency for the calculated models (shown in Figure 4A), and the 3-21G basis set was employed to carry out the DFT-B3LYP calculations. The vibrational frequencies and intensities for the optimized models by the Gaussian 98 program were analyzed by the Gaussview 2.1 program package.

\section{Results and Discussion}

3.1. Heterogeneous Reaction of OCS on MgO in Closed System. Figure 1shows the dynamic changes of in situ DRIFTS spectra for the $\mathrm{MgO}$ sample at $303 \mathrm{~K}$ in closed system after moist OCS/air was added into the in situ infrared chamber for $3 \mathrm{~min}$. The strong peaks of gaseous OCS appeared at 2071 and $2052 \mathrm{~cm}^{-1} \cdot{ }^{14,15,19} \mathrm{~A}$ pair of peaks of gaseous $\mathrm{CO}_{2}$ was observed at 2361 and $2341 \mathrm{~cm}^{-1}$. The bands at $2578 \mathrm{~cm}^{-1}$ is the characteristic frequency of $v_{\mathrm{s}}(\mathrm{SH})$ of surface HS. ${ }^{20,21}$ The peak at $3755 \mathrm{~cm}^{-1}$ for surface hydroxyl ${ }^{22}$ decreased in intensity as a function of time. The bands at 1659 and $1409 \mathrm{~cm}^{-1}$ were assigned to $v_{\text {as }}(\mathrm{OCO})$ and $v_{\mathrm{s}}(\mathrm{OCO})$ of surface $\mathrm{HCO}_{3}{ }^{-}$species, which were accompanied by $v(\mathrm{OH})$ and $\delta(\mathrm{OH})$ at 3618 and $1225 \mathrm{~cm}^{-1}$, respectively. ${ }^{23-26}$ It should be noted that the frequency of $\delta\left(\mathrm{H}_{2} \mathrm{O}\right)$ is also close to $1659 \mathrm{~cm}^{-1}$, which was accompanied by the broad band in the range of 3300-3500 $\mathrm{cm}^{-1}$. Therefore, a similar experiment in dry air was performed. As shown in Figure 2, the intensity for all surface species on $\mathrm{MgO}$ in dry air was lower than that in moist air. This means the reaction was observably affected by water, as will be discussed in detail in section 3.3. However, the peaks at 3618, 1659,1409 , and $1225 \mathrm{~cm}^{-1}$ were also present when trace water was removed. Compared with Figure 1, the intensity of peaks in the range $3300-3500 \mathrm{~cm}^{-1}$ in Figure 2 was very weak while the intensity of the peak at $1659 \mathrm{~cm}^{-1}$ was still strong, indicating that $\mathrm{HCO}_{3}{ }^{-}$was mainly contributing to the band at $1659 \mathrm{~cm}^{-1}$. In addition, a new negative peak at $3701 \mathrm{~cm}^{-1}$ due to the loss of another type of surface $\mathrm{OH}$ was also present, which means there were at least two kinds of surface hydroxyl participating in the reaction. The surface $\mathrm{OH}$ at $3755 \mathrm{~cm}^{-1}$ was more active than that at $3701 \mathrm{~cm}^{-1}$, which corresponds to the basicity sequence of surface $\mathrm{OH}$; namely, the higher the wavenumber, the stronger the basicity for surface $\mathrm{OH} .{ }^{27}$ For both cases, the peak intensities of $\mathrm{CO}_{2}$ at 2341 and $2361 \mathrm{~cm}^{-1}$ increase with time at first and then decrease after a certain time. However, this trend is more obvious in dry air. These phenomena can be attributed to the adsorption process of $\mathrm{CO}_{2}$ and the different surface coverage of bicarbonate and carbonate in moist and dry air. In Figure 2, a new band at $1000 \mathrm{~cm}^{-1}$ belonging to an unknown surface species also appeared.

In order to better understand the surface species, the DRIFTS spectrum in the range of $1150-1750 \mathrm{~cm}^{-1}$ after reaction for 10 min in Figure 1 was fitted by Peakfit based on the secondderivative spectrum, ${ }^{28}$ as shown in Figure 3 with a correlation coefficient of 0.9994 . The bands at 1379 and $1138 \mathrm{~cm}^{-1}$ were assigned to $v_{\text {as }}(\mathrm{SO})$ and $v_{3}(\mathrm{SO})$ of surface $\mathrm{SO}_{4}{ }^{2-}$ species, respectively, ${ }^{29-31}$ and the weak band at $1334 \mathrm{~cm}^{-1}$ is the $\nu_{\text {as }}(\mathrm{SO})$ band of physical adsorbed $\mathrm{SO}_{2} \cdot{ }^{32,33}$ The appearance of a band at $1584 \mathrm{~cm}^{-1}$ indicates the formation of carbonate on the surface of $\mathrm{MgO}$ sample. ${ }^{34}$ The bands at 1651, 1408, and $1220 \mathrm{~cm}^{-1}$ in Figure 3 were assigned to surface $\mathrm{HCO}_{3}{ }^{-23-26}$ Peaks from 1084 to $945 \mathrm{~cm}^{-1}$ (shown in Figures 1 and 2) were due to the absorption of surface $\mathrm{HSO}_{3}{ }^{-}$and $\mathrm{SO}_{3}{ }^{2-} \cdot 24,35,36$ The assignment for the peak at 1273 and $1545 \mathrm{~cm}^{-1}$ is unsure yet and is temporarily marked as $X$.

It can be clearly seen in Figures 1 and 2 that the intensity of peaks of gaseous $\mathrm{OCS}(\mathrm{g})$ and surface $\mathrm{OH}(\mathrm{s})$ decreased with time, accompanied by the increase of $\mathrm{HCO}_{3}{ }^{-}(\mathrm{s}), \mathrm{CO}_{2}(\mathrm{~g})$, $\mathrm{HSO}_{3}{ }^{-} / \mathrm{SO}_{3}{ }^{2-}(\mathrm{s})$, and $\mathrm{SO}_{4}{ }^{2-}(\mathrm{s})$. However, the peak intensity at $1273 \mathrm{~cm}^{-1}$ increased initially and then decreased with time. This suggests that $1273 \mathrm{~cm}^{-1}$ ought to be the band of an intermediate. Furthermore, the intensity of peaks of $\mathrm{HCO}_{3}{ }^{-}$in dry air is lower than that in moist air, while the relative intensity between the peak at 1273 and $1225 \mathrm{~cm}^{-1}$ become stronger in dry air than that in moist air. That means the heterogeneous reaction of OCS on $\mathrm{MgO}$ also took place even without water, but the decomposition rate for intermediate at $1273 \mathrm{~cm}^{-1}$ was restrained to a great extent, which leads to accumulation of the intermediate.

Hoggan et al. ${ }^{37}$ have proposed hydrogen thiocarbonate $\left(\mathrm{HSCO}_{2}{ }^{-}\right)$as the intermediate for hydrolysis of OCS on alumina and have reported the vibrational frequency of $\mathrm{HSCO}_{2}{ }^{-}$at $1572 v_{\mathrm{as}}(\mathrm{OCO})$ and $1327 \mathrm{~cm}^{-1} v_{\mathrm{s}}(\mathrm{OCO})$ on alumina. In our previous studies, we also observed $\mathrm{HSCO}_{2}{ }^{-}$at $1575 \mathrm{~cm}^{-1}$ as the intermediate for heterogeneous reaction of OCS on $\mathrm{Al}_{2} \mathrm{O}_{3}$ using DRIFTS. ${ }^{13-14}$ Because they have the same products, namely, $\mathrm{CO}_{2}$ and $\mathrm{H}_{2} \mathrm{~S}$, the reaction intermediate of OCS on $\mathrm{MgO}$ probably should be the same as that on $\mathrm{Al}_{2} \mathrm{O}_{3}$. If $X$ was related to the intermediate, in other words, $\mathrm{HSCO}_{2}{ }^{-}$on $\mathrm{MgO}$, there was a large discrepancy between the reported frequency in literature $^{13,14,37}$ and our experimental results (Figure 3). Consequently, theoretical calculations were performed to identify the vibrational frequency for $\mathrm{HSCO}_{2}{ }^{-}$on $\mathrm{MgO}$.

3.2. Vibrational Frequency of Hydrogen Thiocarbonate by DFT Calculations. More than 10 kinds of calculated models of $\mathrm{HSCO}_{2}{ }^{-}$on $\mathrm{MgO}$, including monodentate, bidentate, and bridging hydrogen thiocarbonate, were designed for DFT calculations. The bridging hydrogen thiocarbonate model (shown in Figure 4A) is the best one to be in agreement with the experimental results (Figure 3) when calculated vibrational frequency and relative intensity were simultaneously considered. As can be seen in Figure $4 \mathrm{~B}$, the $v_{\mathrm{as}}(\mathrm{OCO})$ vibrational frequency of thiocarbonate was calculated at $1564 \mathrm{~cm}^{-1}$ with 130 $\mathrm{km} \cdot \mathrm{mol}^{-1}$ intensity, which is very close to the experimental value of $1545 \mathrm{~cm}^{-1}$, and the $v_{\mathrm{s}}(\mathrm{OCO})$ vibration frequency was calculated at $1293 \mathrm{~cm}^{-1}$ with $709 \mathrm{~km} \cdot \mathrm{mol}^{-1}$ intensity, corresponding to a strong adsorption at $1273 \mathrm{~cm}^{-1}$ (Figures 1-3). However, as shown in Figures 1 and 2, the peak intensity at $1273 \mathrm{~cm}^{-1}$ increased initially and then decreased with time, while the peak at $1545 \mathrm{~cm}^{-1}$ did not decrease at all due to the 


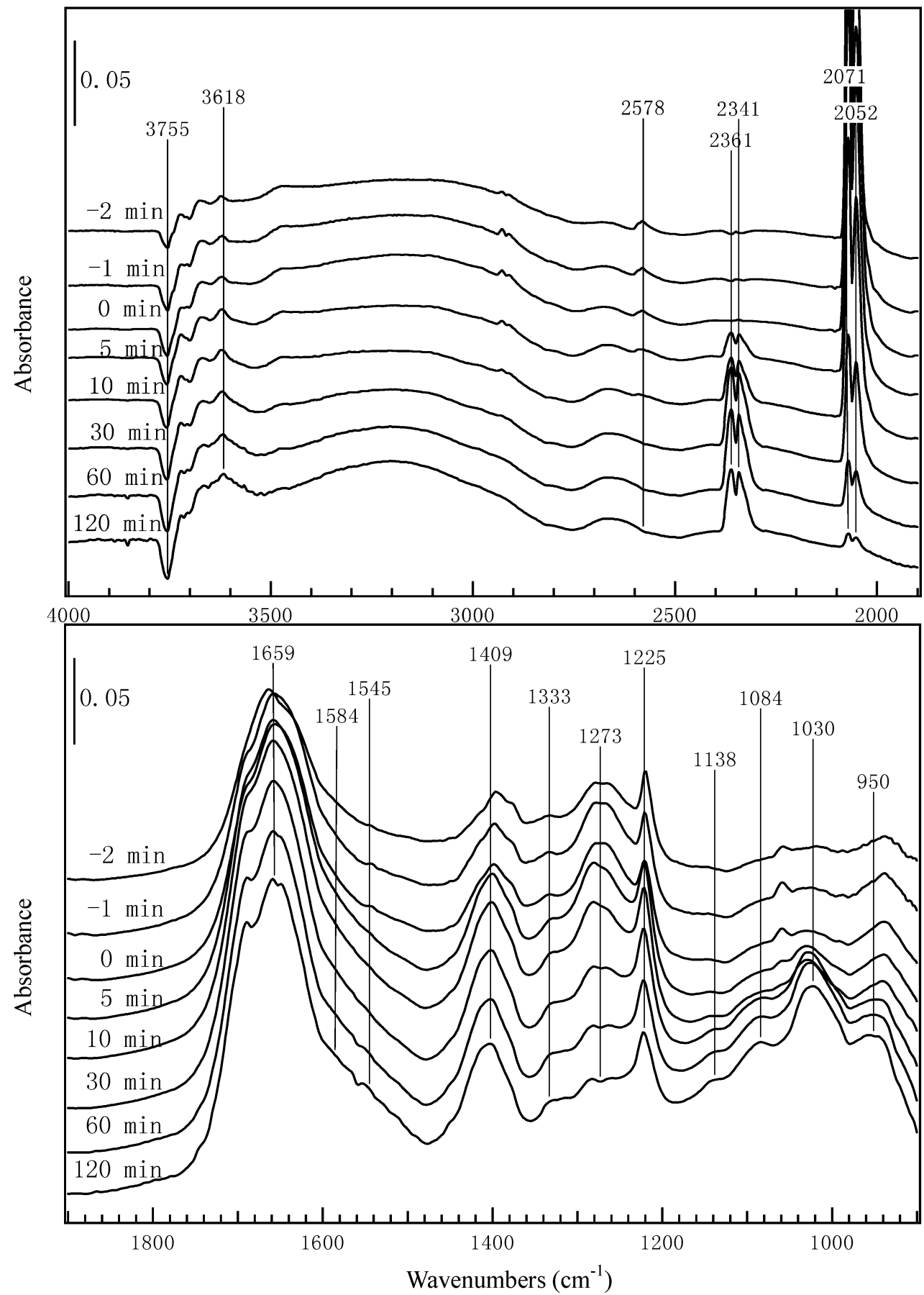

Figure 1. Dynamic changes of in situ DRIFTS spectra in closed system for $\mathrm{MgO}$ at $303 \mathrm{~K}$ after 1000 ppm OCS balanced with moist air was introduced into the in situ infrared chamber. (Negative time denotes the time before the in situ-DRIFTS chamber was closed.)

effect of the strong band at $1584 \mathrm{~cm}^{-1}$ of carbonate. ${ }^{34}$ So, the bands of $X$ at $1273 \mathrm{~cm}^{-1}$ and another band at $1545 \mathrm{~cm}^{-1}$ can be assigned to $v_{a \mathrm{~s}}(\mathrm{OCO})$ and $v_{\mathrm{s}}(\mathrm{OCO})$ of $\mathrm{HSCO}_{2}^{-}$on $\mathrm{MgO}$.

\subsection{Heterogeneous Reaction of $\mathrm{OCS}$ on $\mathrm{MgO}$ in Flow} System. In order to analyze the gaseous products and to investigate the effects of oxygen, surface hydroxyl, and water on the heterogeneous reaction, the experiments were performed in a flow system. The dynamic changes of in situ DRIFTS spectra of $\mathrm{MgO}$ were measured in the flow system upon sequential introduction of dry OCS/ $\mathrm{N}_{2}$ and dry OCS/air. Gaseous products were simultaneously analyzed by QMS on-line, and the results are presented in Figure 5-7.

Figure 5 shows the mass spectrum of gaseous products of 1000 ppm OCS in dry nitrogen and dry air at $303 \mathrm{~K}$ over $\mathrm{MgO}$. There are four main peaks at mass numbers of $34,44,60$, and
64 in the range of 33-70 amu, which belong to $\mathrm{H}_{2} \mathrm{~S}, \mathrm{CO}_{2}, \mathrm{OCS}$, and $\mathrm{SO}_{2}$ respectively. The peak at 44 also includes the CS fragment peak of OCS, and the peak at 48 is the SO fragment peak of $\mathrm{SO}_{2}$. Therefore, we can conclude that gaseous products of heterogeneous reaction of OCS over $\mathrm{MgO}$ include $\mathrm{CO}_{2}, \mathrm{H}_{2} \mathrm{~S}$, and $\mathrm{SO}_{2}$

Figure 6 shows the dynamic changes of in situ DRIFTS spectra for the $\mathrm{MgO}$ sample exposed to a flow of dry $1000 \mathrm{ppm}$ of OCS/ $\mathrm{N}_{2}$ and then dry OCS/air at $303 \mathrm{~K}$. The surface HS, which is formed from the dissociative adsorption of $\mathrm{H}_{2} \mathrm{~S}$ on $\mathrm{MgO},{ }^{38,39}$ was observable in dry nitrogen (Figure 6A, spectra $\mathrm{a}-\mathrm{d}$ ), while it decreased quickly when $\mathrm{O}_{2}$ was introduced into the feed gas (Figure 6A, spectra $\mathrm{e}-\mathrm{h}$ ). We also observed the decrease of $\mathrm{HS}$ at $2578 \mathrm{~cm}^{-1}$ in intensity as a function of time in Figures 1 and 2. The band at $1333 \mathrm{~cm}^{-1}$ for $\mathrm{SO}_{2}{ }^{32,33}$ increased 

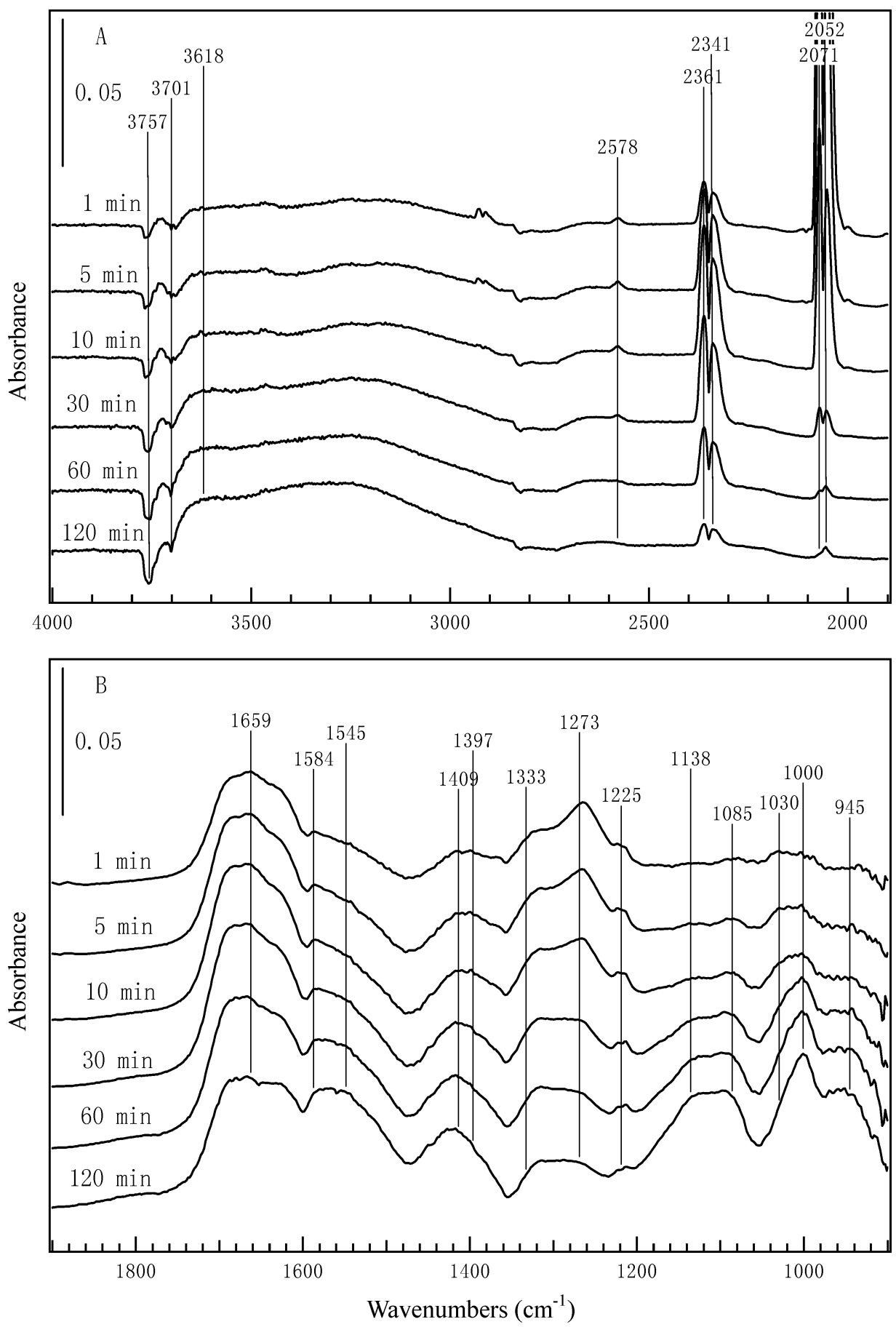

Figure 2. Dynamic changes of in situ DRIFTS spectra in closed system for MgO at $303 \mathrm{~K}$ after 1000 ppm OCS balanced with dry air was introduced into the in situ infrared chamber.

initially (Figure 6B) and then decreased when $\mathrm{O}_{2}$ was introduced into the system, which was accompanied by the increase in intensity of surface sulfate at 1178 and $1138 \mathrm{~cm}^{-129,31}$ and surface sulfite in the range of $1084-950 \mathrm{~cm}^{-1} \cdot 24,35,36$ This means gaseous $\mathrm{SO}_{2}$ is related to the oxidation of $\mathrm{H}_{2} \mathrm{~S}$ or surface $\mathrm{HS}$ by surface oxygen species and then $\mathrm{SO}_{2}$ is further oxidized to surface sulfite and sulfate by gaseous oxygen or surface oxygen.

Even without water in the feed gas, heterogeneous reaction of OCS on $\mathrm{MgO}$ also took place for a moment, which was well supported by DRIFTS spectra (Figures 2 and 6) and mass spectroscopy for gaseous products (Figure 5). Therefore, it can be deduced that surface $\mathrm{OH}$ is related not only to the formation of $\mathrm{HSCO}_{2}{ }^{-}$but also to the decomposition of $\mathrm{HSCO}_{2}{ }^{-}$to produce $\mathrm{HCO}_{3}{ }^{-}, \mathrm{CO}_{2}$, and $\mathrm{H}_{2} \mathrm{~S}$. Liu et al. ${ }^{14}$ also reported surface $\mathrm{OH}$ on $\mathrm{Al}_{2} \mathrm{O}_{3}$ has an important effect on the reaction rate of OCS on $\mathrm{Al}_{2} \mathrm{O}_{3}$. Figure 7 shows the effect of $\mathrm{H}_{2} \mathrm{O}$ on the reaction of OCS over $\mathrm{MgO}$. After reaction with 1000 ppm OCS in moist $\mathrm{N}_{2}$ for $30 \mathrm{~min}$, the $\mathrm{MgO}$ sample was purged with $\mathrm{N}_{2}$ till the gaseous OCS disappeared thoroughly (Figure 7, spectra a), and then purged with moist simulated air for $180 \mathrm{~min}$ (Figure 7 , spectra b). The intensity of $\mathrm{HSCO}_{2}{ }^{-}\left(1273 \mathrm{~cm}^{-1}\right)$ and surface $\mathrm{OH}\left(3757 \mathrm{~cm}^{-1}\right)$ decreased remarkably as shown in Figure 7. However, the decrease at $1545 \mathrm{~cm}^{-1}$ is not clear due to the effect of the strong band at $1584 \mathrm{~cm}^{-1}$ from carbonate. ${ }^{34}$ This means that surface $\mathrm{OH}$ also participates in the decomposition of $\mathrm{HSCO}_{2}{ }^{-}$even in the presence of $\mathrm{H}_{2} \mathrm{O}$ in the reaction system. On the other hand, when $\mathrm{O}_{2}$ was introduced into the feed gas, the intensity in the range of $3300-3500 \mathrm{~cm}^{-1}$ increased a little, 


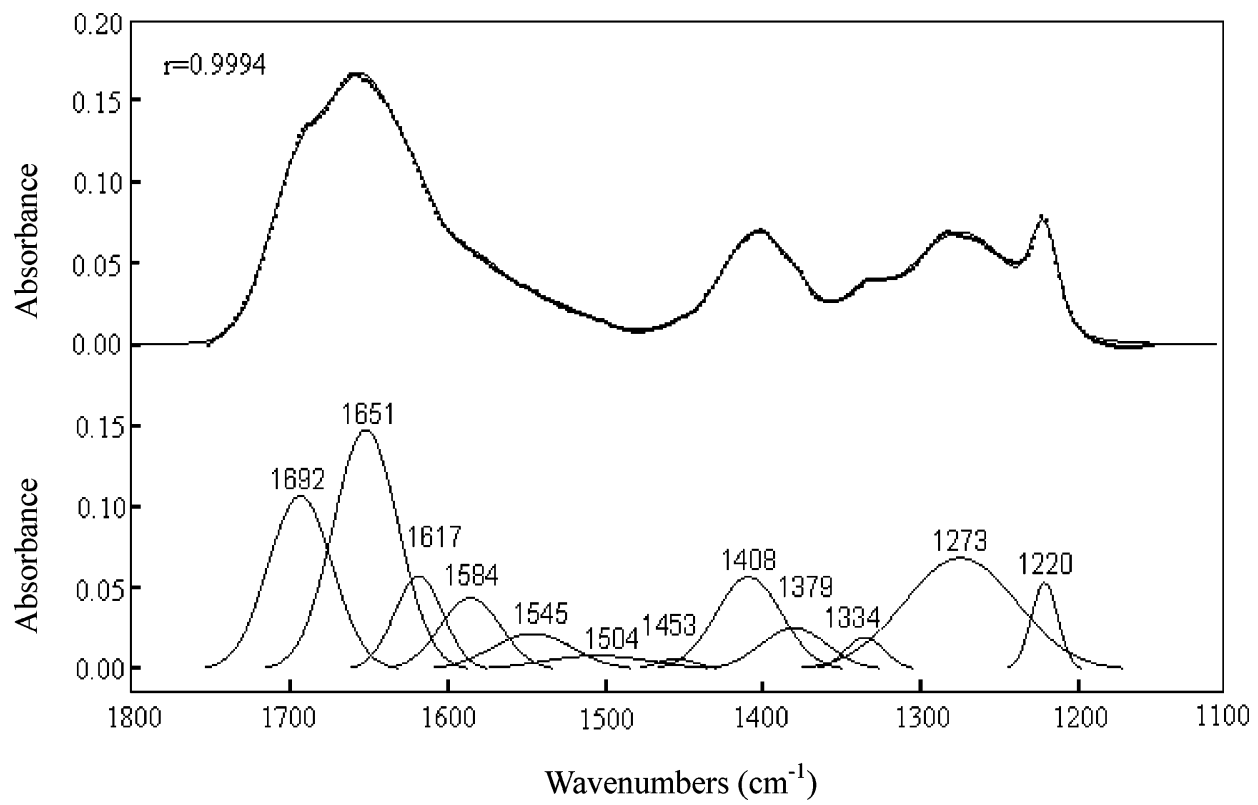

Figure 3. Peak fit of DRIFTS spectrum in the range of $1150-1750 \mathrm{~cm}^{-1}$ after reaction for 10 min in Figure 1.

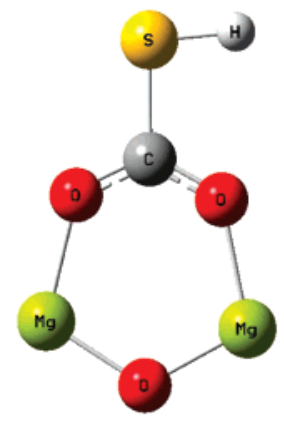

(A)

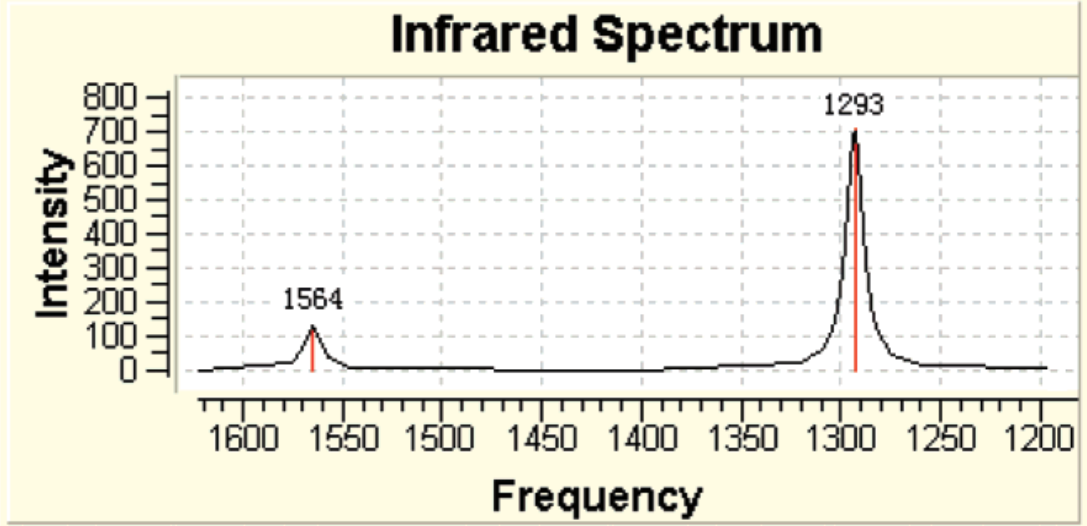

(B)

Figure 4. (A) Optimized configuration of adsorption model for $\mathrm{HSCO}_{2}^{-}$on $\mathrm{MgO}$ and (B) calculated vibrational IR spectrum for $\mathrm{HSCO}_{2}{ }^{-}$.

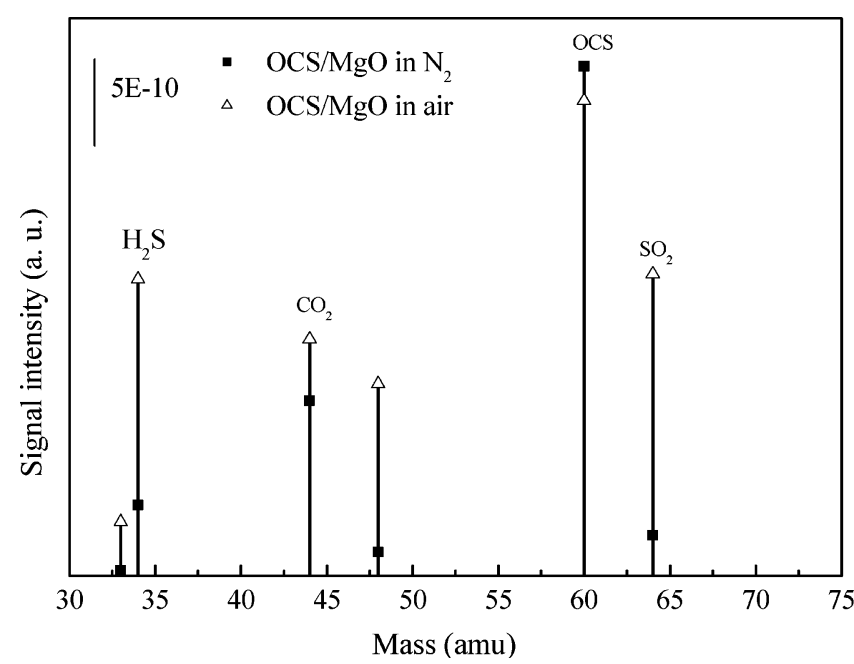

Figure 5. Mass spectra of gaseous products for $1000 \mathrm{ppm}$ OCS on $\mathrm{MgO}$ in dry $\mathrm{N}_{2}$ and in dry air.

as shown in Figure 6, because of the formation of $\mathrm{H}_{2} \mathrm{O}$ from $\mathrm{H}_{2} \mathrm{~S}$ or surface $\mathrm{HS}$ oxidized by $\mathrm{O}_{2}$ or surface $\mathrm{O}^{40}$ The newly formed water promotes the hydrolysis of OCS to give rise to more $\mathrm{H}_{2} \mathrm{~S}$ and $\mathrm{CO}_{2}$ in turn. Therefore, the QMS signal of gaseous $\mathrm{H}_{2} \mathrm{~S}$ in the presence of $\mathrm{O}_{2}$ is much stronger than that in the absence of $\mathrm{O}_{2}$ in Figure 5. It is well-known that there exists a balance between surface hydroxyl and gaseous water on metal oxides. Accordingly, the lost surface hydroxyl can be compensated partially by gaseous water, which promotes further reaction between surface $\mathrm{HSCO}_{2}{ }^{-}$and surface $\mathrm{OH}$ in the moist reaction system.

3.4. Mechanism of Heterogeneous Reaction of OCS on MgO. Because the (100) face is the most stable face for $\mathrm{MgO}$ (Figure 8A), $38,41,42$ the active site, which includes two adjacent surface hydroxyls and one Lewis acid site of magnesium, was put forward as shown in Figure 8B. The possible mechanism of heterogeneous reaction of OCS on $\mathrm{MgO}$ could be proposed on the basis of the above results as shown in Figure 9.

First, OCS is adsorbed on the surface of $\mathrm{MgO}$ and reacts with surface $\mathrm{OH}$ to form surface $\mathrm{HSCO}_{2}{ }^{-}$(I). Type I hydrogen thiocarbonate can be transformed to another type of $\mathrm{HSCO}_{2}{ }^{-}$(II), accompanied by positive charge transfer from the neighboring Lewis acid site of $\mathrm{Mg}$. Unfortunately, the characteristic frequency of $\mathrm{HSCO}_{2}^{-}$(I) was not observed, probably due to the fast transformation from $\mathrm{HSCO}_{2}{ }^{-}$(I) to $\mathrm{HSCO}_{2}{ }^{-}$(II). In general, the ring structure is favorable in energy; its calculated adsorptive energy is $-103.93 \mathrm{~kJ} \cdot \mathrm{mol}^{-1}$, while that 


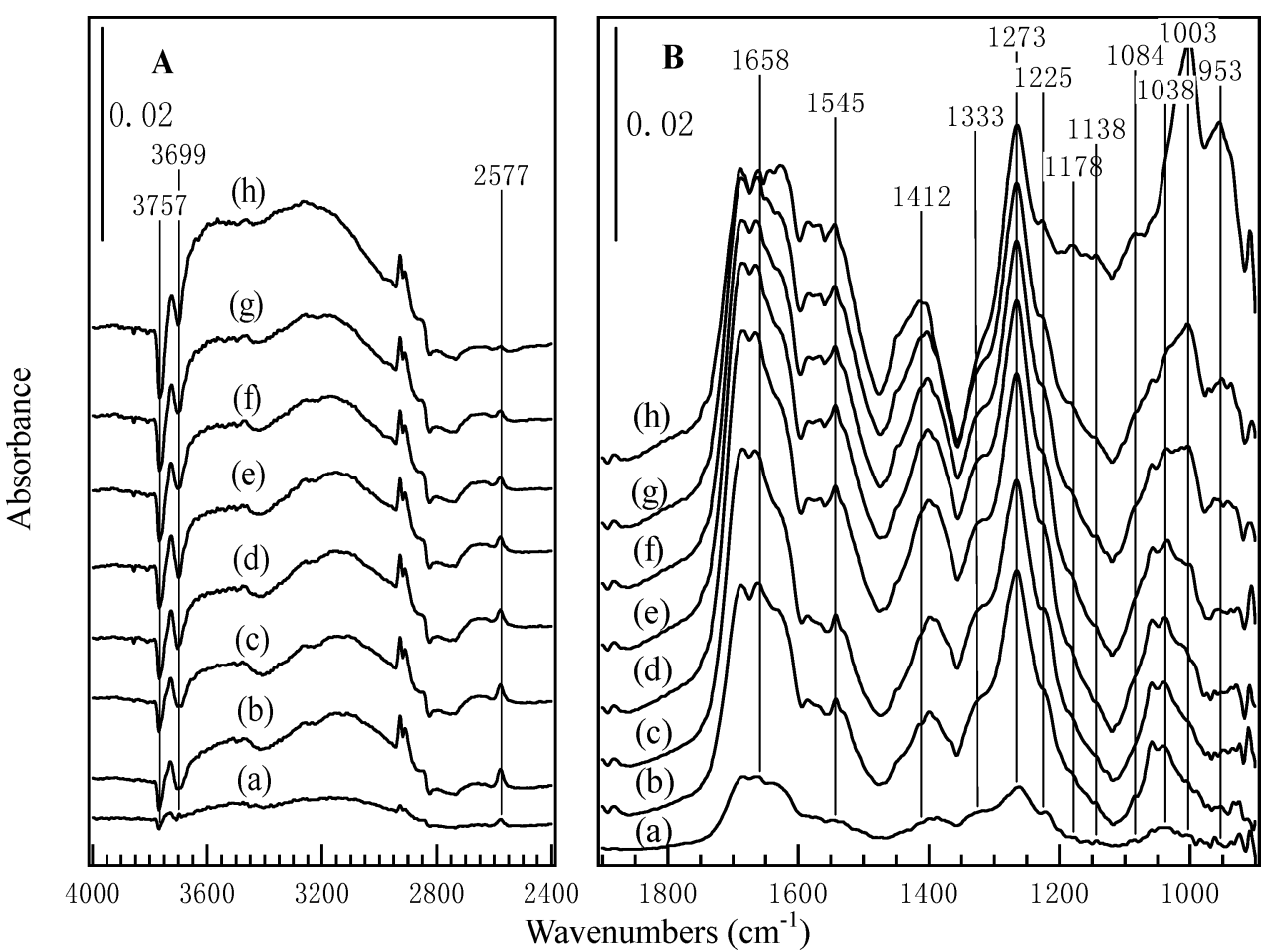

Figure 6. Dynamic changes of in situ DRIFTS spectra for $\mathrm{MgO}$ in $1000 \mathrm{ppm}$ OCS in dry $\mathrm{N}_{2}$ and then in dry air at $303 \mathrm{~K}$ in flow system: (a) 1 min in $\mathrm{N}_{2}$; (b) 5 min in $\mathrm{N}_{2}$; (c) $10 \mathrm{~min}$ in $\mathrm{N}_{2}$; (d) 30 min in $\mathrm{N}_{2}$; (e) 1 min in air; (f) 5 min in air; (g) $10 \mathrm{~min}$ in air; (h) $30 \mathrm{~min}$ in air.

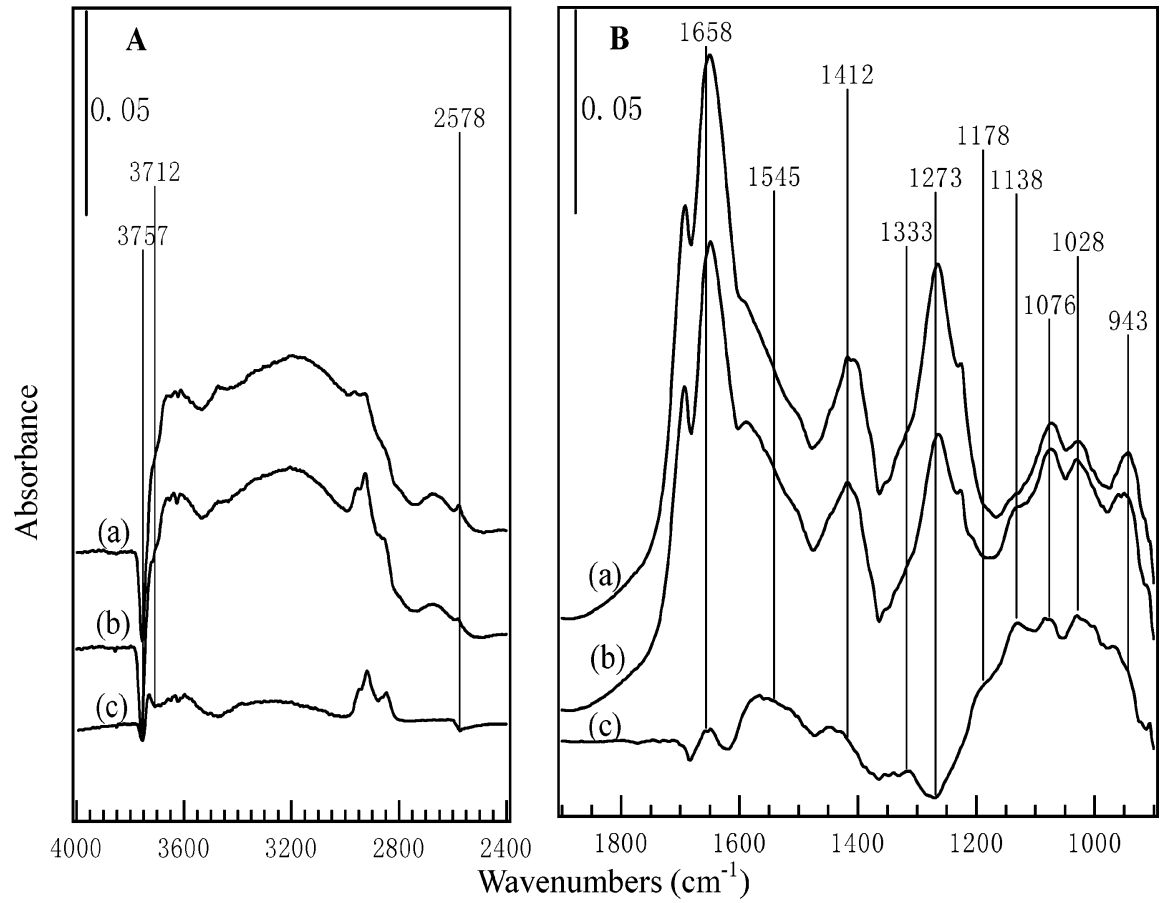

Figure 7. In situ DRIFTS spectra for MgO/OCS in undried flow system at $303 \mathrm{~K}$. (a) MgO reacts with 1000 ppm OCS in $\mathrm{N}_{2}$ for 30 min and then the system is purged with $\mathrm{N}_{2}$ utill the gaseous OCS disappears thoroughly. (b) The sample is purged with simulated air for 180 min. (c) The subtracted spectrum of $\mathrm{b}$ and $\mathrm{a}$.

for $\mathrm{HSCO}_{2}^{-}$(I) is $-102.50 \mathrm{~kJ} \cdot \mathrm{mol}^{-1}$. Therefore, the main surface species for $\mathrm{HSCO}_{2}{ }^{-}$is bridging hydrogen thiocarbonate. The second step of heterogeneous reaction is the decomposition of $\mathrm{HSCO}_{2}{ }^{-}$attacked by another adjacent surface $\mathrm{OH}$ to produce hydrogen sulfide and bicarbonate. If water is acquirable, the lost surface hydroxyl can be compensated partially by gaseous water, which promotes further reaction between surface $\mathrm{HSCO}_{2}{ }^{-}$ and surface $\mathrm{OH}$. Finally, $\mathrm{H}_{2} \mathrm{~S}$ can be dissociatively adsorbed on $\mathrm{MgO}$ to generate surface $\mathrm{HS}$ and then oxidized to $\mathrm{S}, \mathrm{SO}_{2}$, and $\mathrm{HSO}_{3}{ }^{-} / \mathrm{SO}_{3}{ }^{2-}$ and $\mathrm{SO}_{4}{ }^{2-}$ by gaseous oxygen or surface oxygen anion radical $\left(\mathrm{O}_{2}^{-}\right) \cdot{ }^{43}$

\section{Conclusion and Environmental Implication}

This study revealed that OCS could be catalytically hydrolyzed by surface hydroxyl on $\mathrm{MgO}$ and then the sulfur species can be catalytically oxidized on $\mathrm{MgO}$ surface to produce sulfite and sulfate under ambient conditions. Surface hydrogen thiocarbonate was found to be a key intermediate formed by the 


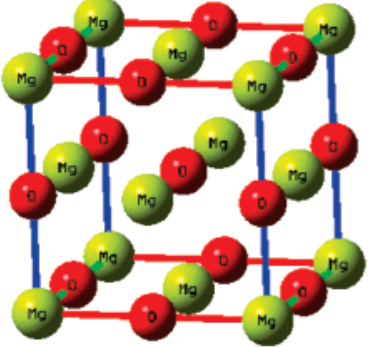

(A)

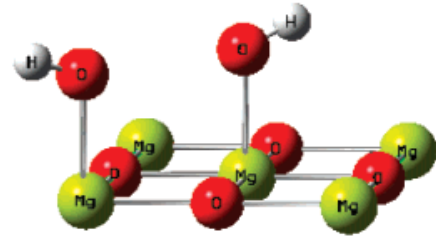

(B)
Figure 8. (A) Crystal structure of periclase $(\mathrm{MgO})$ and (B) the structure of active site on $\mathrm{MgO}$ (100) face.
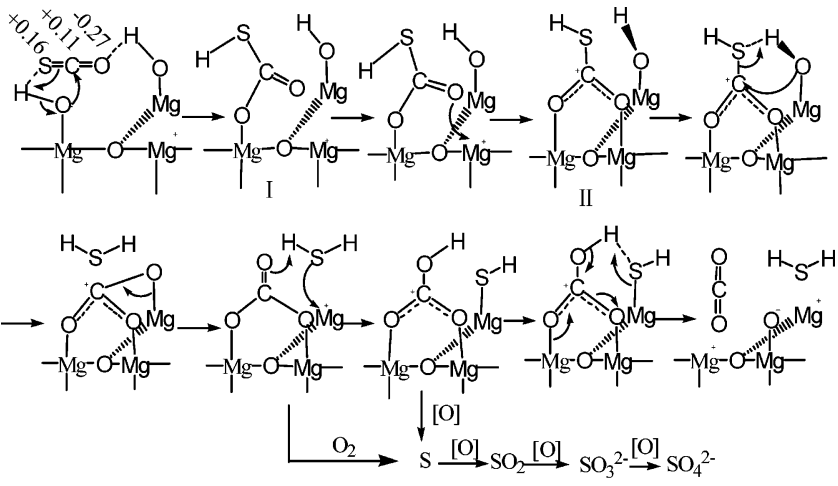

Figure 9. Mechanism of heterogeneous reaction of OCS on $\mathrm{MgO}$.

reaction of OCS with surface hydroxyl. Carbon dioxide, hydrogen sulfide, and sulfur dioxide were also found as the main gaseous products by further reaction between surface hydroxyl and hydrogen thiocarbonate. Surface sulfate is the deep oxidization product of sulfur-containing species through intermediates including sulfide, sulfur, sulfur dioxide, and sulfite in sequence.

Although the content of $\mathrm{MgO}$ in mineral atmospheric particles is only $6.1 \mathrm{wt} \%$, which is much lower than that of $\mathrm{SiO}_{2}$ and $\mathrm{Al}_{2} \mathrm{O}_{3}$, the basicity of $\mathrm{MgO}\left(\mathrm{p} K_{\mathrm{a}}=9 \sim 10\right)$ is much stronger than that of $\mathrm{SiO}_{2}\left(\mathrm{p} K_{\mathrm{a}} \leq 7\right)$ and $\mathrm{Al}_{2} \mathrm{O}_{3}\left(\mathrm{p} K_{\mathrm{a}}=7 \sim 8\right),{ }^{26,42,44}$ which is a favorable factor for the hydrolysis of OCS. In addition, because the typical relative humidity in environment is in the range of $20-80 \%$, the active site proposed as above can be easily formed by the adsorption of water on the surface of $\mathrm{MgO}$. Therefore, the reaction of OCS on $\mathrm{MgO}$ may be an important path for heterogeneous reaction of OCS on atmospheric particulates. Of course, the similarities and differences among different metal oxides as well as the real mineral particles and the uptake coefficient of OCS on these particles should be studied in detail in future work.

Acknowledgment. This research was financially supported by the National Natural Science Foundation of China (50621804) and 973 Program (2007CB407301).

\section{References and Notes}

(1) Turco, R. P.; Whitten, R. C.; Toon, O. B.; Pollack, J. B.; Hamill, P. Nature 1980, 283, 283-286. 9005.

(2) Chin, M.; Davis, D. D. J. Geophys. Res. 1995, 100 (DS), 8993-

(3) Watts, S. F. Atmos. Environ. 2000, 34, 761-799.

(4) Kjellström, E. J. Atmos. Chem. 1998, 29, 151-177.

(5) Crutzen, P. J. Geophys. Res. Lett. 1976, 3, 73-76.

(6) Protoschill-Krebs, G.; Wilhelm, C.; Kesselmeier, J. Atmos. Environ. 1996, 30, 3151-3156.

(7) Ravishankara, A. R. Science 1997, 276, 1058-1065. 1058

(8) Andreae, M. O.; Crutzen, P. J. Science 1997, 276, 1052-

(9) Usher, C. R.; Michel, A. E.; Grassian, V. H. Chem. Rev. 2003 $103,4883-4939$

(10) Grassian, V. H. J. Phys. Chem. A 2002, 106, 806-877.

(11) Ding, J.; Zhu, T. Chin. Sci. Bull. 2003, 48, 2005-2013.

(12) Corn, M.; Montgomery, T. L.; Reitz, R. J. Science 1968, 159, $1350-1351$

(13) He, H.; Liu, J. F.; Mu, Y. J.; Yu. Y. B.; Chen, M. X. Environ. Sci. Technol. 2005, 39, 9637-9642.

(14) Liu, J. F.; Yu, Y. B.; Mu, Y. J.; He, H. J. Phys. Chem. B 2006, $110,3225-3230$

(15) West, J.; Williams, B. P.; Young, N.; Rhodes, C.; Hutchings, G. J. Catal. Commun. 2001, 2, 135-138.

(16) Wu, H. B.; Wang, X.; Cheng, J. M.; Yu, H. K.; Xu, H. X.; Pan, X X.; Hou, H. Q. Chin. Sci. Bull. 2004, 49, 739-743.

(17) Zhang, Z. Q.; Friedlander, S. Environ. Sci. Technol. 2000, 34 4687-4694.

(18) Frisch, M.; Foresman, J.; Frisch, A.; et al. Gaussian 98. Gaussian Inc.: Pittsburgh, PA, 1998.

(19) Tubergen, M. J.; Lavrich, R. J.; McCargar, J. W. J. Chem. Educ. 2000, 77, 163-165.

(20) Isoniemi, E.; Petterson, M.; Khriachtchev, L. Lundell, J.; Räsänen, M. J. Phys. Chem. A 1999, 103, 679-685.

(21) Datta, A.; Cavell, R. G. J. Phys. Chem. 1985, 89, 450-454.

(22) Peri, J. B.; Hannan, R. B. J. Phys. Chem. 1960, 64, 15261530.

(23) Morterra, C.; Zecchina, A.; Coluccia, S.; Chiorino, A. J. Chem Soc., Faraday Trans. 1977, 73, 1544-1560.

(24) Lavalley, J. C. Catal. Today 1996, 27, 377-401.

(25) Amenomiya, Y.; Morikawa, Y.; Pleizier, G. J. Catalysis 1977, 46, 431-433.

(27) Turek, A. M.; Wachs, I. E.; DeCanio, E. J. Phys. Chem. 1992, 96 , $5000-5007$

(28) O’Grady, A.; Dennis, A. C.; Denvir, D.; McGarvey, J. J.; Bell, S. E. J. Anal. Chem. 2001, 73, 2058-2065.

(29) Ivanovski, V.; Petruševski, V. M. J. Mol. Struct. 2003, 645, 273279.

(30) Bensitel, M.; Waqif, M.; Saur, O.; Lavalley, J. C. J. Phys. Chem. 1989, 93, 6581-6582.

(31) Wu, Q.; Gao, H. W.; He, H. J. Phys. Chem. B 2006, 110, 83208324

(32) Datta, A.; Cavell, R. G. J. Phys. Chem. 1985, 89, 454457.

(33) Schneider, W. F.; Li, J.; Hass, K. C. J. Phys. Chem. B 2001, 105 , 6972-6979.

(34) Baltrusaitis, J.; Jensen, J. H.; Grassian, V. H. J. Phys. Chem. B 2006, 110, 12005-12016.

(35) Goodman, A. L.; Li, P.; Usher, C. R.; Grassian, V. H. J. Phys. Chem. A 2001, 105, 6109-6120.

(36) Miller, F. A.; Wilkings, C. H. Anal. Chem. 1952, 24, 1253-1294.

(37) Hoggan, P. E.; Aboulayt, A.; Pieplu, A.; Lavalley, J. C. J. Catal. 1994, 149, 300-306.

(38) Rodriguez, J. A.; Maiti, A. J. Phys. Chem. B 2000, 104, 36303638.

(39) Lavalley, J. C.; Travert, J.; Chevreau, T.; Lamotte, J.; Saur, O. J. C. S. Chem. Commun. 1979, 4, 146-148.

(40) Liu, C. L.; Chuang, T. T.; Dalla Lana, I. G. J. Catal. 1972, 26 474-476.

(41) Valentin, C. D.; Pacchioni, G.; Abbet, S.; Heiz, U. J. Phys. Chem. $B$ 2002, 106, 7666-7673.

(42) Al-Abadleh, H. A.; Grassian, V. H. Surf. Sci. Rep. 2003, 52, 63161.

(43) Sawai, J. J. Microbiol. Methods 2003, 54, 177-182.

(44) Martin, D.; Duprez, D. J. Phys. Chem. 1996, 100, 94299438. 